\title{
Landscape-scale forest structure in northern New York and potential successional impacts of the 1998 ice storm $^{1}$
}

\author{
by Benjamin D. Rubin ${ }^{2}$ and Paul D. Manion ${ }^{2}$
}

\begin{abstract}
Damage from the 1998 ice storm was evaluated on 50 plot clusters (1667 trees) in northern New York. For seven of the 10 most dominant species, observed diameter distributions fit those predicted by the best fit negative exponential model according to Chi-square analysis $\left(\chi^{2}, \alpha=0.05\right)$. The lack of fit for Pinus resinosa, Fraxinus nigra and Tsuga canadensis was attributed to plantation management, variable flooding regimes and harvesting practices, respectively. Trees were then removed from the distributions based on the severity of the ice storm damage. Acer saccharum and Populus tremuloides distributions became significantly different from negative exponential, indicating a possible change in population structure that could impact forest succession.
\end{abstract}

Key words: ice storm, forest structure, diameter distribution

Les dommages provoqués par la tempête de verglas de 1998 ont été évalués dans 50 parcelles en grappe (1167 arbres) dans le nord de l'État de New York. Dans le cas de sept des 10 espèces dominantes, les distributions de diamètre observées correspondaient à celles prédites par le meilleur modèle exponentiel de correspondance négative suivant une analyse Chi-carré $\left(\chi^{2}, \alpha=0.05\right)$. Le manque de correspondance pour Pinus resinosa, Fraxinus nigra et Tsuga canadensis a été attribué respectivement à l'aménagement des plantations, aux régimes hydriques et aux pratiques de récolte variables. Les arbres ont été par la suite retirés des distributions selon l'importance des dégâts provoqués par la tempête de verglas. Les distributions d'Acer saccharum et de Populus tremuloides sont devenues significativement différentes du modèle exponentiel, indiquant un changement probable dans la structure des populations qui pourrait avoir un impact sur la succession forestière.

Mots-clés: verglas, structure forestière, distribution des diamètres

\section{Introduction}

The broad scale 1998 ice storm in parts of New England, northern New York and eastern Canada caused locally severe damage to trees intermixed with spotty areas of only moderate or slight damage. Whether damage will have a noticeable affect on forest structure or succession at a landscape scale is important. One way to determine broad scale affects is to sample forest damage at random locations within a large geographical area determining the species and size distributions that were present both independently of the ice storm and considering its possible impact.

Several authors have suggested ways in which information about forest structure, specifically diameter distributions of single and multi species populations, can be used to form hypotheses and derive conclusions about forest structure and succession. Meyer (1952) observed that negative exponential diameter distributions (constant percent decrease in density per unit of diameter) were characteristic of large old growth forests. He, and others since (Leak 1964, Schmelz and Lindsey 1965, Tardif et al. 1994, Leak 1996, Tardif and Bergeron 1999) interpreted the negative exponential distribution as an indicator of equilibrium forest structure. Others disagree and have suggested that other diameter distributions should be considered balanced either instead of or in addition to the negative exponential form (Goff and West 1975, West et al. 1981, Lorimer and Frelich 1984, Goodburn and Lorimer 1999).

\footnotetext{
${ }^{1}$ Paper presented at the Ice Storm 1998 Forest Research Conference, Ottawa, October 19-22, 2000.

${ }^{2}$ Department of Environmental and Forest Biology, SUNY College of Environmental Science and Forestry, Syracuse, NY 13210, (315-470-6783), bdrubin@mailbox.syr.edu,pdmanion@mailbox.syr.edu
}

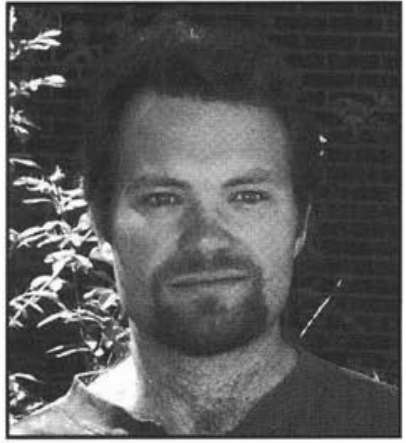

Benjamin Rubin

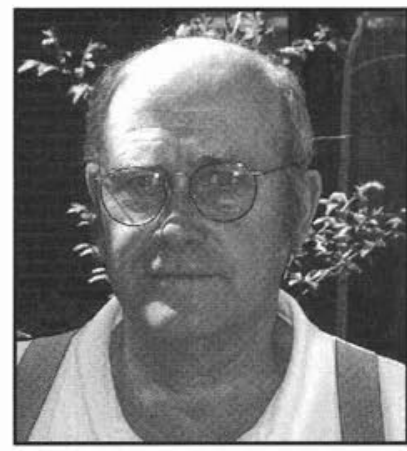

Paul D. Manion
However, most of the non-negative exponential distributions were observed for stands (Goff and West 1975, Lorimer and Frelich 1984, Goodburn and Lorimer 1999). Often, many non-negative exponential stand level distributions form a negative exponential distribution when aggregated as a sample of a larger area (Meyer 1952, Goff and West 1975). Most studies that have addressed diameter distributions at broad spatial scales have observed negative exponential distributions (Meyer 1952, Leak 1996, Manion and Griffin 2001). In contrast, West et al. (1981) who provided no quantitative assessment considered the landscape distribution non-negative exponential.

Manion and Griffin (2001) used the constant mortality per dbh class, characteristic of a negative exponential distribution, to calculate a baseline or expected mortality level for single species and mixed species populations over a landscape. They developed the Phoenix helix model for characterizing forest health based on the relationship between observed mortality and a predicted baseline mortality derived from the negative exponential 


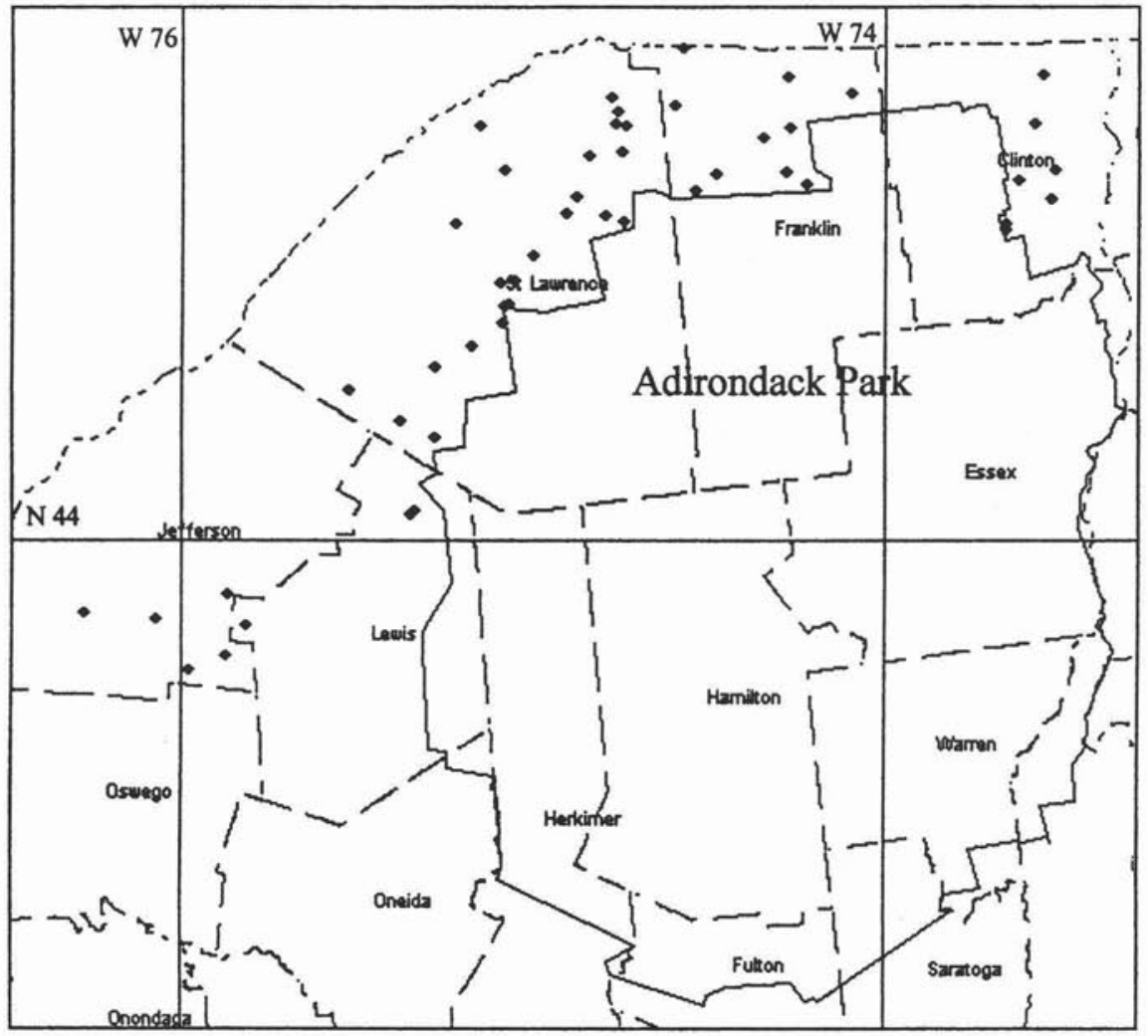

Fig. 1. Map of northern New York showing locations of sampling plot clusters.

diameter distribution. Manion et al. (2001) applied the model to an ice storm damage survey for northern New York State.

We are currently evaluating the hypothesis that potential consequences of ice storm damage on forest community structure and succession can be detected from changes in the diameter distributions of important species. The objectives of this paper are to 1) statistically test the assumption of the Phoenix helix model that diameter distributions are negative exponential by analyzing the shapes of diameter distributions from the ice storm-damaged region of New York without considering possible ice storm-related mortality, 2) evaluate whether potential ice storm-related mortality is likely to change the form of diameter distributions of major species, and 3) interpret the possible affects of such changes on forest structure and succession.

\section{Materials and Methods}

During the summers of 1998 and 1999, ice storm damage to 7329 trees was measured on 201 plot clusters in northern New York. Each cluster was composed of three 10 basal-areafactor prism points, their centres arranged at the corners of a right triangle with two equal sides of $60 \mathrm{~m}$. The prism points were used to sample living and dead trees of $9.0 \mathrm{~cm}$ dbh and greater. Several variables were recorded for each tree, however, only dbh, measured in $0.254 \mathrm{~cm}$ ( 0.1 in) units, species and numbers of live and broken branches ( $\geq 5 \mathrm{~cm}$ diameter at break) were used in this analysis. Branches of each tree were placed into one of the following categories: living, dead, ripped off at base and broken beyond the base. We counted a maximum of 20 branches per tree in each category. To obtain the percent broken, the sum of broken and ripped off branches was divided by the sum of broken, ripped off and living branches). The broken or living count was increased by one to represent the main stem depending on whether the main bole was broken or not.

For this analysis, all plots within the Adirondack Park were excluded leaving 50 plot clusters, containing 1667 trees (Fig. 1). This sub-sample was chosen in order to confine the analysis to the area that was ice damaged and to increase homogeneity among plots with respect to management, successional stage and elevation. Many of these plots have been thinned in the past and are at early to middle stages of succession. They received varying intensities of ice storm damage.

In order to convert trees sampled to trees per ha each tree received an expansion factor equal to the reciprocal of the plot size (determined from dbh) on which it was found (Shiver and Borders 1996). The diameter distribution was analyzed for the 10 dominant species (red maple (Acer rubrum L.), sugar maple (Acer saccharum Marshall.), trembling aspen (Populus tremuloides Michx.), eastern hemlock (Tsuga canadensis (L.) Carrière), red pine (Pinus resinosa Ait.), northern white cedar (Thuja occidentalis L.), black ash (Fraxinus nigra Marshall.), black cherry (Prunus serotina Ehrh.), American beech (Fagus grandifolia Ehrh.), and white ash (Fraxinus americana L.)). For each species, a best fit linear regression was calculated for the natural logarithm of density of live trees by $2.54-\mathrm{cm}$ (1-inch) dbh classes from $9 \mathrm{~cm}$ up to the class immediately preceding the first empty (zero density) class. This eliminated problems of taking the natural log of zero and relatively large sampling errors at the large end of the diameter distribution.

In order to conduct a $\chi^{2}$ test the density of trees per ha predicted by the regression equation for each $2.54-\mathrm{cm}$ dbh class was converted into an expected number of trees for the actual sampling area. Since dbh was initially measured in $0.254-\mathrm{cm}$ 
(0.1-inch) units, each dbh class is actually an aggregation of ten dbh sub-classes. Each sub-class corresponds to a 0.254-cm unit with a specific plot area and predicted density. The predicted density of the entire dbh class can be described as the sum of the predicted density of each of these ten dbh sub-classes:

$$
\mathrm{D}=\sum \mathrm{d}_{\mathrm{i}}
$$

Where $D$ is the predicted density of the entire dbh class; $d_{i}$ is the predicted density for a 0.254 in sub-class within that dbh class and $\mathrm{i}=1$ to 10 . The slope of the regression of the 2.54-cm dbh classes was used to describe the density of each $0.254-\mathrm{cm}$ sub-class, from the second smallest $\left(\mathrm{d}_{2}\right)$ to the largest $\left(\mathrm{d}_{10}\right)$, in terms of the adjacent smaller sub-class:

$$
\ln \left(\mathrm{d}_{\mathrm{i}}\right)=(1+(0.1 \times \mathrm{a})) \times \ln \left(\mathrm{d}_{(\mathrm{i}-1)}\right)
$$

Where $\mathrm{a}$ is the regression slope $\left(\mathrm{ha}^{-1} / 2.54 \mathrm{~cm}\right)$. Within each 2.54-cm dbh class, equation (1) was combined with the nine possible iterations of equation (2) to yield ten equations which were solved for the ten predicted densities, $d_{1}$ through $d_{10}$.

To calculate the expected number of trees in the sub-class the predicted densities of each sub-class $\left(\mathrm{d}_{\mathrm{i}}\right)$ were multiplied by the area of the plot on which that sub-class was sampled and by the number of plots in the data set. Within each $2.54-\mathrm{cm} \mathrm{dbh}$ class, the expected number of trees for each sub class were summed to yield the total expected number of trees for the dbh class.

Next, the distribution of observed trees in the sample were compared to the number predicted by regression using a $\chi^{2}$ test $(\alpha=0.05)$. Comparisons were made based on the expected and observed number of trees in all dbh classes smaller than the class where the expected number of trees fell below 1 .

Finally, all trees with $100 \%$, and $75 \%$ or greater $(\geq 5 \mathrm{~cm}$ diameter) branch breakage were removed separately. This generated two scenarios of low and high levels of predicted ice storm mortality, respectively. For each scenario, a new regression line for each species was calculated. The $\chi^{2}$ analyses described above were repeated for each mortality scenario using the new observed densities and a new regression line.

For both the original and simulated populations of black ash, the smallest empty dbh class was $25 \mathrm{~cm}$. For the low and high mortality simulation scenarios of northern white cedar, the smallest empty class was $18 \mathrm{~cm}$. For both species, the small number of classes used resulted in a regression that was clearly not representative of the entire diameter distribution. If one tree had been observed for the empty class, the point would have been below the regression line. Therefore, it would be illogical to ignore the empty class since doing so would result in a higher predicted density when no trees were found than if one tree had been found. This problem was resolved by calculating the logarithm of density as if 1 tree had been found. From that value, we subtracted the change in logarithm of density that would have resulted from finding a second tree. This small surrogate value appropriately contributed to the fit of a new regression line calculated over a wider, more representative range of dbh classes.

\section{Results \\ Initial diameter distributions}

The $\chi^{2}$ tests demonstrated that seven of the 10 species had negative exponential diameter distributions (Fig. 2 and Table 1). Red pine, black ash and eastern hemlock were the species with

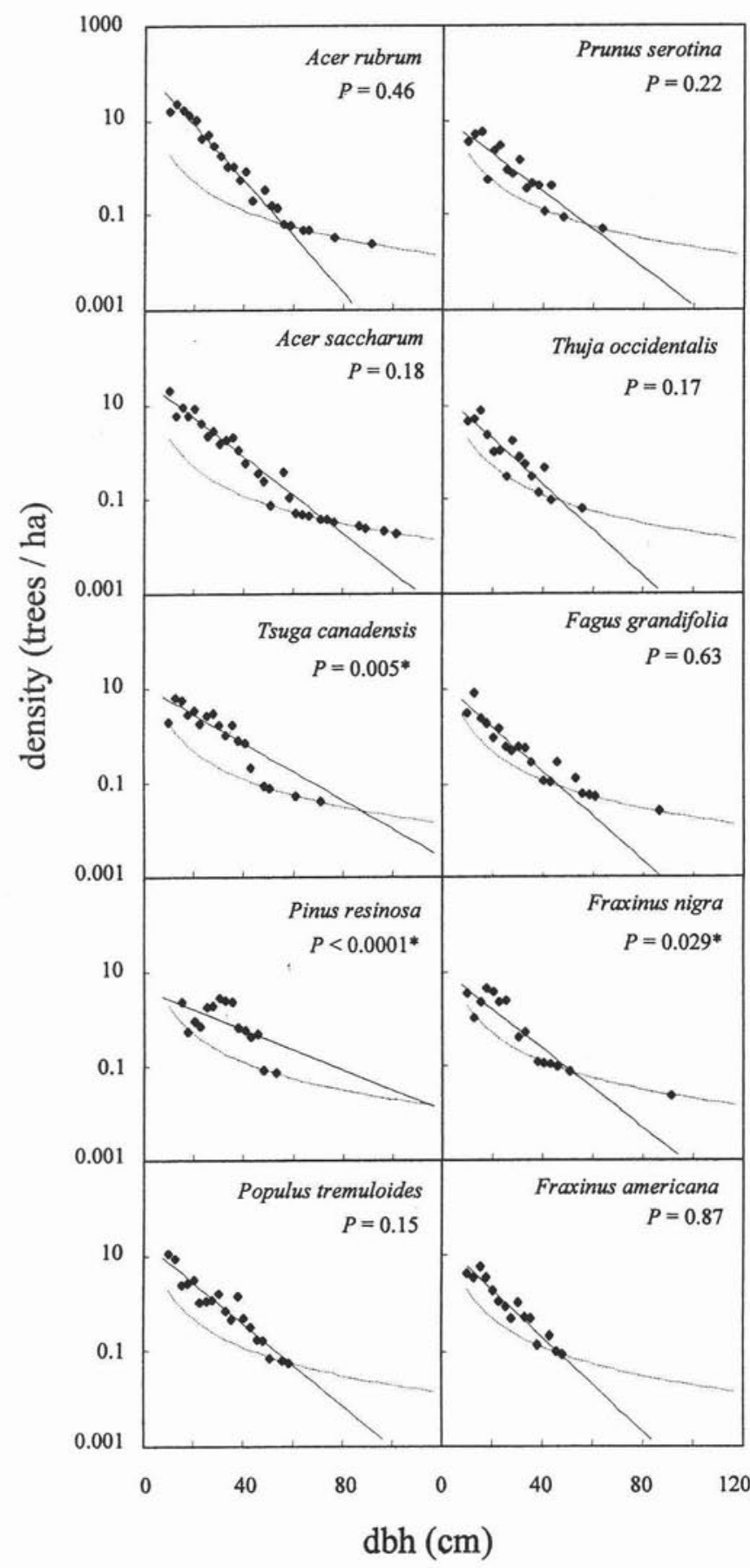

Fig. 2. Pre-ice damage diameter distributions by species. Each graph shows the regression line fit to the natural logarithm of the diameter distribution (solid, straight line), the density that would be represented by one tree of each dbh class found in the entire sample (dotted, arced line), the observed density distribution (black dots), the species name and the $P$ value associated with the $\chi^{2}$ test. * indicates significance at $\alpha=0.05$ level. Chi-square tests are based on the range of diameters where the predicted density is greater than the density represented by one tree.

observed diameter distributions that differed significantly from negative exponential form. Red pine had very few small trees, including no regeneration below $16 \mathrm{~cm} \mathrm{dbh}$. The diameter distribution of black ash was generally negative exponential. 
Table 1. Regression slope (In density $\left(\mathrm{ha}^{-1}\right)$ per $2.54-\mathrm{cm}$ dbh class) and intercepts (In density $\left(\mathrm{ha}^{-1}\right)$ ), and $P$ values for $\chi^{2}$ tests of predicted to observed diameter distributions for initial diameter distributions and distributions that result from low and high mortality simulations

\begin{tabular}{|c|c|c|c|c|c|c|c|c|c|}
\hline \multirow[b]{2}{*}{ Species } & \multicolumn{3}{|c|}{$\begin{array}{c}\text { Initial Diameter } \\
\text { Distributions }\end{array}$} & \multicolumn{3}{|c|}{$\begin{array}{l}\text { Low Mortality Scenario } \\
\text { (trees with } 100 \% \text { branch } \\
\text { breakage removed) }\end{array}$} & \multicolumn{3}{|c|}{$\begin{array}{l}\text { High Mortality Scenario } \\
\text { (trees with } \geq 75 \% \text { branch } \\
\text { breakage removed) }\end{array}$} \\
\hline & slope & intercept & $P$-value & slope & intercept & $P$-value & slope & intercept & $P$-value \\
\hline A. rubrum & -0.34 & 4.77 & 0.46 & -0.35 & 4.56 & 0.19 & -0.33 & 4.33 & 0.35 \\
\hline A. saccharum & -0.24 & 3.58 & 0.18 & -0.22 & 3.24 & $0.04 *$ & -0.22 & 3.25 & $0.03 *$ \\
\hline T. canadensis & -0.18 & 2.47 & $0.005 *$ & -0.15 & 2.11 & $0.0002 *$ & -0.15 & 2.11 & $0.001^{*}$ \\
\hline P. resinosa & -0.13 & 1.49 & $0.0000^{*}$ & -0.13 & 1.49 & $0.0000 *$ & -0.13 & 1.49 & 0.0000 * \\
\hline P. tremuloides & -0.25 & 3.00 & 0.15 & -0.23 & 2.72 & 0.23 & -0.26 & 2.79 & $0.02 *$ \\
\hline P. serotina & -0.23 & 2.46 & 0.22 & -0.23 & 2.46 & 0.22 & -0.23 & 2.43 & 0.16 \\
\hline T. occidentalis & -0.28 & 2.84 & 0.17 & -0.27 & 2.45 & 0.19 & -0.27 & 2.45 & 0.18 \\
\hline F. grandifolia & -0.27 & 2.64 & 0.63 & -0.26 & 2.41 & 0.40 & -0.29 & 2.57 & 0.69 \\
\hline F. nigra & -0.24 & 2.39 & $0.03 *$ & -0.20 & 1.97 & $0.01 *$ & -0.23 & 2.11 & $0.01 *$ \\
\hline F. americana & -0.29 & 2.93 & 0.87 & -0.29 & 2.70 & 0.87 & -0.28 & 2.71 & 0.88 \\
\hline
\end{tabular}

* Significant at $\alpha=0.05$ level by $\chi^{2}$ test.

However, between $9 \mathrm{~cm}$ and $25 \mathrm{~cm}$ dbh there was minimal decrease in density. Densities of eastern hemlock were below predicted levels for dbh greater than $43 \mathrm{~cm}$.

\section{Diameter distributions with simulated ice storm mortality}

The ten species examined had varying levels of ice storm damage (Table 2). Red pine and black cherry sustained little or no ice related mortality under either predicted ice storm mortality scenarios. Diameter distributions for trembling aspen under the high mortality scenario and for sugar maple under both low and high mortality scenarios changed from negative exponential to non-negative exponential distributions (Table 1). All other species with initially negative exponential distributions maintained negative exponential distributions under both simulated mortality scenarios. No species changed from a non-negative exponential to a negative exponential distribution due to either mortality scenario (Table 1).

The two species that were altered from negative exponential diameter distributions by simulated mortality showed different potential responses to the ice event. The high mortality scenario for trembling aspen decreased the density of trees below $30 \mathrm{~cm}$ dbh by $19 \%$ and for trees above $30 \mathrm{~cm}$ dbh $26 \%$, indicating heavy damage over a wide range of diameters but possibly more severe impacts to larger trees. On the other hand, most of the damage to sugar maple occurred in the smaller $\mathrm{dbh}$ classes (15\% density decrease below $30 \mathrm{~cm} \mathrm{dbh}$ and $2 \%$ density decrease above $30 \mathrm{~cm} \mathrm{dbh}$ ).

\section{Discussion \\ Initial diameter distributions}

In general, the analysis confirms that negative exponential diameter distributions are common for a number of forest tree species when populations are examined across the landscape as suggested by the Phoenix helix model (Manion and Griffin 2001). Past management or disturbance has likely modified the populations with non-negative exponential distributions. The imbalance of the red pine distribution is probably due to management. Eighty-one percent of total basal area of red pine in the sample is in plantations. It is theoretically possible for a group of plantations to form a balanced distribution, with more or less constant new plantings. However, in recent decades new plantations have not been created (no red pine $<16 \mathrm{~cm}$ dbh in our sample). Therefore, as the plantations are
Table 2. Basal area $\left(\mathrm{m}^{2} \mathrm{ha}^{-1}\right)$ by species of initial sample and under low and high mortality simulations

\begin{tabular}{lccc}
\hline \multicolumn{1}{c}{ Species } & Initial & $\begin{array}{c}\text { Low } \\
\text { mortality }\end{array}$ & $\begin{array}{c}\text { High } \\
\text { mortality }\end{array}$ \\
\hline A. rubrum & 2.82 & 2.31 & 2.16 \\
A. saccharum & 2.43 & 2.20 & 2.17 \\
T. canadensis & 1.44 & 1.30 & 1.30 \\
P. resinosa & 1.32 & 1.32 & 1.32 \\
P. tremuloides & 1.21 & 1.10 & 0.95 \\
P. serotina & 0.84 & 0.84 & 0.82 \\
T. occidentalis & 0.75 & 0.55 & 0.55 \\
F. grandifolia & 0.73 & 0.64 & 0.59 \\
F. nigra & 0.70 & 0.65 & 0.65 \\
F. americana & 0.70 & 0.58 & 0.56 \\
\hline
\end{tabular}

cut or the trees die for other reasons red pine populations in northern New York will probably be replaced by more locally adapted, native species regardless of the ice storm damage.

Chi square analysis reveals that the diameter distribution of black ash is not negative exponential. The relatively constant density of black ash across a range of dbh classes could be explained by a recruitment pulse when the current $18-27-\mathrm{cm}$ trees were being recruited or by a temporary deficit when the current $9-18-\mathrm{cm}$ trees were recruited. The timing and intensities of flooding might cause such changes in the reproductive success of a population. Tardif and others (1994) found that the diameter distributions of two black ash populations in Quebec fit a model of constant mortality well, but that residuals could be correlated with changes in annual precipitation. In a separate study Tardif and Bergeron (1999) found one of six black ash populations experienced a recruitment pulse such as we observed in our data, and they attribute it to changes in flooding regimes. Both of their studies were conducted in bottomlands where flooding is frequent. The black ash in the present sample of northern New York were found on sites with similar hydrologic regimes. Sixty-six percent of the basal area of black ash in the sample was found on sites with standing water and $31 \%$ was found on plots where the soil was moist to very wet. Only $2 \%$ of the total black ash basal area in the sample was found on well-drained sites, although $55 \%$ of the plots were well drained.

Selective harvesting of large trees caused the non-exponential pattern of the pre-ice storm eastern hemlock diameter distri- 
bution. Harvesting had removed $75 \%$ of the basal area above $43 \mathrm{~cm}$ and $13 \%$ of the basal area of smaller trees. This type of distribution may return to a negative exponential form if cutting is discontinued. However, if selective cutting practices continue, the imbalanced successional status of eastern hemlock will likely remain.

\section{Diameter distributions with simulated ice storm mortality}

There is no documentation of the actual mortality associated with various levels of ice storm damage. However, some authors (Shortle and Smith 1998, Miller-Weeks et al. 1999, Van Dyke 1999) suggest, based on expert opinion, that $75 \%$ or greater crown loss may significantly increase the probability of mortality. Such opinions are comparable to our simulated mortality levels. The susceptibility of individual species to ice storm breakmge is also poorly understood (Manion et al. 2001).

Chi square analysis demonstrated that five of the seven pecies with negative exponential diameter distributions would Onaintain negative exponential distributions even if all trees with б $5 \%$ or more branch breakage were killed. This suggests a minImal impact of the ice storm on the overall size class distribution and sustainability of these species. The analysis also suggests त़hat the population structures of trembling aspen and sugar maple inay be altered by the ice storm.

7 Trembling aspen is an early successional transition species That undergoes prolific clonal reproduction, resulting in stands केf trees with similar diameters. Other, shade tolerant species gro usually able to establish themselves under these canopies vini eventually take over the canopy as the relatively short-lived Tiespens die. Other species already established in the trembling ven dominated stands that were damaged could be released Firem competition or suppression by the death of damaged trees gigi the normal successional pattern could be facilitated by the क्षेe storm damage.

Seven of our plots had $\geq 5 \%$ branch breakage across all species gffld $\geq 20 \%$ basal area in trembling aspen. On these plots, क्षrembling aspen accounted for $54 \%$ of the basal area and had In average of $41 \%$ branch breakage. The next most dominant Epecies on these sites (between 2\% and 10\% basal area each and accounting for $36 \%$ basal area as a group) were northern White cedar, red maple, balsam fir (Abies balsamea (L.) Giller.), American elm (Ulmus americana L.), yellow birch (Betufa alleghaniensis Britt.), eastern hop-hornbeam (Ostrya virginiana Miller) K. Koch.) and black cherry. Of these, red maple and कु lack cherry were heavily damaged by the ice storm (average कf 29\% and 55\% branch breakage, respectively). Eastern hopdornbeam does not grow large enough to dominate the canopy Fef a mature stand. Therefore, white cedar, balsam fir, yellow birch and elm (all of which received $\leq 7 \%$ branch breakage from the ice storm) may become more dominant in these stands if damage to trembling aspen proves lethal.

Because sugar maple is a climax species, the heavy damage to small trees and, potential disruption of the diameter distribution could persist for a long time. Codominant species (American beech, white ash, red maple, and eastern hemlock) in heavily damaged sugar maple stands ( $\geq 5 \%$ branch breakage, $\geq 20 \%$ basal area in sugar maple) all experienced similar levels of damage to sugar maple (24\% to $53 \%)$. Since no species will gain a competitive advantage from the ice storm damage, a significant species shift is unlikely in these stands.
The $\chi^{2}$ tests were employed in this study to differentiate between negative exponential distributions and non-negative exponential distributions. However, changes from one negative exponential distribution to another have not been tested. Furthermore, background information for interpreting potential successional consequences of such a shift is not available. It is possible therefore, that other species such as red maple, northern white cedar, black ash, white ash, eastern hemlock and American beech may also experience biologically meaningful changes in diameter distributions. Also, testing whether diameter distribution models besides negative exponential fit the data presented is beyond the scope of this paper.

\section{Summary and Conclusion}

The diameter distributions of most of the dominant species examined in the study area were negative exponential. Distributions of red pine, black ash, and eastern hemlock are most likely altered because of plantation management, variable flooding regimes and harvesting practices, respectively. Species examined in this study can be grouped into three categories of ice storm damage. Category one is species that may experience altered population structure in response to the ice storm damage. The ice storm will likely lead to altered dbh class structures for trembling aspen and sugar maple. If trembling aspen experiences significant storm related mortality northern white cedar, balsam fir, yellow birch, or American elm may be the replacement species. If sugar maple experiences significant ice breakage related mortality, it could disproportionately disrupt the diameter distribution affecting the long-term abundance of this species across the landscape. The second category is species for which no change in diameter distribution was detected, but which have suffered substantial ice storm breakage: red maple, northern white cedar, black ash, white ash, eastern hemlock and American beech. The third category is red pine and black cherry species for which minimal ice damage was recorded and no change in diameter distribution was detected.

\section{Acknowledgements}

This investigation was funded by the New York State Center for Forestry Research and Development, the New York State Department of Environmental Conservation, the USDA Forest Service, and the Edna Bailey Sussman Fund.

\section{References}

Goff, F.G. and D. West. 1975. Canopy-understory interaction effects on forest population structure. For. Sci. 21: 98-108.

Goodburn, J.M. and C.G. Lorimer. 1999. Population structure in old-growth and managed northern hardwoods: an examination of the balanced diameter distribution concept. For. Ecol. and Manage. 118: $11-29$.

Leak, W.B. 1964. An expression of diameter distribution for unbalanced, uneven-aged stands and forests. For. Sci. 10: 39-50.

Leak, W.B. 1996. Long-term structural change in uneven-aged northern hardwoods. For. Sci. 42: 160-165.

Lorimer, C.G. and L.E. Frelich. 1984. A simulation of equilibrium diameter distributions of sugar maple (Acer saccharum). Bull. Tor. Bot. Club. 111: 193-199.

Manion, P.D. and D.H. Griffin. 2001. Large landscape scale analysis of tree death in the Adirondack Park, New York. For. Sci. (in press). Manion, P.D., D.H. Griffin and B.D. Rubin. 2001. Ice damage impacts on the health of the northern New York State forest. For. Chron. 77(4): 619-625.

Meyer, H.A. 1952. Structure, growth, and drain in balanced unevenaged forests. J. For. 50: 85-92. 
Miller-Weeks, M., C. Eager and C.M. Petersen. 1999. The northeastern ice storm 1998: a forest damage assessment: Northeast Forester's Association.

Schmelz, D. and A.A. Lindsey. 1965. Size-class structure of old-growth forests in Indiana. For. Sci. 11: 258-264.

Shiver, B.D. and B.E. Borders. 1996. Sampling techniques for forest resource inventory. New York: John Wiley.

Shortle, W.C. and K.T. Smith. 1998. Prospects for recovery. In L.C. Irland. Ice storm 1998 and the forests of the Northeast. J. For. 96: 32-40.

Tardif, J. and Y. Bergeron. 1999. Population dynamics of Fraxinus nigra in response to flood-level variations in northwestern Quebec. Ecol. Monogr. 69: 107-125.
Tardif, J., S. Dery and Y. Bergeron. 1994. Sexual regeneration of black ash (Fraximus nigra Marsh.) in a boreal floodplain. Am. Midl. Nat. 132: 121-135.

Van Dyke, O.1999. A literature review of ice storm impacts on forests in eastern North America. SCSS Technical Report \#112. Ontario Ministry of Natural Resources.

West, D.C., H.H. Shugart and R.W. Ranney. 1981. Population structure of forests over a large area. For. Sci. 27: 701-710. 